\title{
Perceived University Students' Attributions of Their Academic Success and Failure
}

\author{
Kitila A. K. Mkumbo ${ }^{1}$ \& Jacqueline Amani ${ }^{2}$ \\ ${ }^{1}$ School of Education, University of Dar es Salaam, Dar es Salaam, Tanzania \\ ${ }^{2}$ Mkwawa University College of Education, Private Bag, Iringa, Tanzania \\ Correspondence: Kitila A. K. Mkumbo, School of Education, University of Dar es Salaam, P.O Box 35048, Dar es \\ Salaam, Tanzania. Tel: 255-754-301-908. E-mail: kitilam@udsm.ac.tz
}

Received: January 1, 2012

Accepted: March 2, 2012 Published: June 1, 2012

doi:10.5539/ass.v8n7p247

URL: http://dx.doi.org/10.5539/ass.v8n7p247

\begin{abstract}
This study examined the applicability of the attribution theory in understanding how students attribute their academic success and failure. Participants involved a sample of 260 undergraduate students at the University of Dar es Salaam, Tanzania. They completed an attitude questionnaire scale with items on locus of control, stability and controllability dimensions. The results show that the majority of students attributed their academic performance to internal, stable and controllable factors. High performing students were more likely to attribute their academic performance to internal and controllable factors than low performing students. Success was attributed to internal and controllable factors, while academic failure was attributed to external and uncontrollable factors. Save for sex, the participants' demographic variables did not statistically significantly influence the attribution pattern. The results of this study confirm the predictions of the attribution theory and are in line with the findings of similar studies conducted in other university settings.
\end{abstract}

Keywords: attribution, academic performance, academic success, academic failure, Tanzania

\section{Introduction: The Attribution Process and Motivation for Academic Achievement}

Naturally, human beings are in constant search for the factors that cause them or other people to behave the way they do. The process of assigning causes to our or other people's behaviour is called attribution. According to Heider (1958), people broadly attribute the causes of their behaviour either to internal or external factors. An internal attribution (also called personal or dispositional attribution) refers to causes that are associated with the person's innate characteristics such as personality traits, moods, attitudes, abilities or efforts. An external attribution (also called situational attribution), on the other hand, refers to the causes that are external to the person, such as the actions of others, environmental situation or luck.

The attribution theory has been applied in various contexts. It has been applied, for example, in understanding people's decisions about health behaviours, in explaining how people attribute their success or failure in a task and in explaining differences in motivation between high and low achievers (Batool, Arif \& Ud Din, 2010; Laherand \& Putnina, 2007, Murray \& Thomson, 2009). One area that has received considerable attention in social psychological research with regard to the application of attribution theory is its application in explaining success or failure in academic context, with Bernard Weiner as the main theorist.

According to attribution theory, success or failure in academic tasks is associated with three sets of characteristics (Weiner, 1985). Firstly, people may succeed or fail because of internal or external factors, that is, because of factors that originate from within themselves or because of factors that originate in their environment. Secondly, the causes of success or failure may be either stable or unstable. If people believe that the factors are stable, then they may believe that the outcome of their performance is likely to be the same next time they attempt the same or similar task. If the factors are unstable, it means that they can be changed and therefore the outcome of performance may be different next time a behaviour is performed. Thirdly, the causes of success or failure may be either controllable or uncontrollable. If the causes are controllable, then it means that people believe that they can alter these causes. But, on the other hand, if people believe that the causes are uncontrollable, it means that they cannot be altered easily.

The attribution theory assumes that people will attribute their success or failure to factors that will enable them to feel as good as possible about themselves. To avoid negative emotional reactions, people have a tendency to 
attribute success to their own efforts or abilities, but they tend to attribute failure to some external factors that they do not have control of (Augoustinos, 2005).

Accordingly, learners tend to attribute their success at examinations to their efforts or abilities, but they will attribute failure to some environmental factors, such as bad teaching, bad luck or lack of teaching and learning facilities. This implies that people's perceptions or attributions for success or failure will determine the amount of effort the person is willing to expend on a particular activity. Impliedly, therefore, people who attribute a cause to external factors are less likely to put more effort on a task than those who attribute internally.

In educational context, Weiner (1985) identified four attribution factors that are related to academic success or failure, namely: ability, task difficulty, effort and luck. Probably effort is the most important factor in which learners can exercise a great deal of control. Task difficulty is an external and a stable factor, which is clearly beyond the learner's control. Though ability is relatively an internal factor, the learner does not have much control over it because it is a stable factor that cannot easily be changed. Luck is an external and unstable factor and, as such, the learner does have a very little control over it.

Persistence is another important determinant in learners' success in academic endeavours (Lei, 2009). According to Lei, learners will be most persistent at academic tasks if they attribute their academic success to internal, unstable factors that they have control, such as effort. It follows that for students to be able to persist at academic activities, they need to believe that they are competent and that by working hard they can be successful. Students are also more likely to do better in their future academic task if they attribute their current failure to a lack of appropriate effort, and the role of the teacher in this case is to foster a belief in students that they can always do better by putting more effort in their academic tasks. Thus, it is generally best for students to believe that it is their own behaviour rather than external factors that leads to success or failure. However, it is also equally important for students to realise the influence of the environment that surrounds them which might affect their success, and therefore they should avoid overestimating their abilities.

\subsection{Context and Purpose of the Present Study}

In recent years, the attribution theory of achievement motivation and emotion (Weiner, 1985) has received considerable attention in social psychological research. Furthermore, there have been a considerable number of studies investigating the attribution patterns with regard to success and failure in academic context with varying findings and conclusions. These studies generally support the assumption made by the attribution theory that students who achieve high in academic tasks tend to associate their success to internal factors such as ability, effort and having worked hard, while those who do not perform well tend to attribute their failure to external factors, such as bad luck, bad teaching and poor learning environment.

For example, Linder and Janus (1997) examined the relationship between the perception of dental students on how much control they had over their environment and their academic achievement. Findings indicated a significant relationship between locus of control and academic achievement, with students who performed highly in their academic tasks attributing their success to internal factors, while those who performed poorly attributing their failure to external factors.

In another study involving 110 Brazilian students, Boruchovitch (2004) investigated how students attribute their performance in Mathematics. He found that students who performed poorly attributed their failure to external factors, such as examination difficulty and bad luck, while those who performed well attributed their success to internal factors such as being calm and working hard. However, they also attributed their success to some external factors, such as having good teachers and easy examinations. Boruchovitch concluded that both external and internal attributions are made when students explain their success, but they seldom attribute internally when explaining their failure. Similar findings have previously been observed in other countries, such as Japanese, Turkish and Chinese students (Keith, Pottebaun, Sheila \& Eberthat, 1986; Brown, Gray \& Ferrara, 2005).

Apart from locus of control, controllability is another important dimension in Weiner's attribution theory that has received considerable attention in social psychological research. Studies indicate that, of the four attributes in the Weiner's attribution theory, ability, task difficulty, effort and luck, only effort can be under individual's control (Hunter \& Barker, 1987; Lei, 2009). This implies that students need to bank more on effort if they are to be successful in their academic endeavours than other attributes, which they may not have direct control. Indeed, Banks and Woofson (2008) have observed that students' perception of uncontrollability has the most damaging consequences in terms of academic performance. Banks and Woofson conducted a study among 53 British secondary school students investigating their perception of academic performance. The results indicated that students who perceived to be in control of their academic task performed better than those who attributed their performance to some uncontrollable factors.

It is clear that attributions have a significant effect on students' academic achievement, and that the process of attribution is affected by, among other factors, the context in which the attributions are made. Previous studies 
have mainly focused on students at lower levels of education and there are only a few studies involving students in higher education, particularly in Sub-Saharan Africa. Furthermore, previous studies have not systematically examined the variation in attribution of academic achievement between low and high performing students, as well as variation in attribution among students in different academic disciplines and specialisations.

The purpose of the present study was to assess the variation in attribution of academic achievement between high performing and low performing university students. More specifically, the study addressed the following research questions. First, is there a statistically significant difference in attribution of academic achievement between students who 'succeeded' and those who 'failed' in an examination? Second, is there a statistically significant variation in attribution of academic achievement between high and low performing students? Third, how does students' attribution of academic achievement vary across sex, age and academic specialisations or discipline? The attribution pattern was assessed with respect to the three dimensions of the Weiner's attribution theory, namely locus of control, controllability and stability dimensions.

\section{Method}

\subsection{Sample and Participant Selection}

Participants for this study were 260 undergraduate students of the University of Dar es Salaam (158 male, 102 female) who completed a questionnaire on attribution scale. Their age ranged between 20 and 40 years (mean age $=24.6, \mathrm{SD}=2.8$ ).

To enrol participants into the study, an advertisement was posted on University notice boards requesting for volunteers to complete a questionnaire in which 260 students responded. These came from various colleges and schools, with a majority of them coming from the College of Arts and Social Sciences (CASS, 33.1\%), College of Engineering and Technology (COET, 18.1\%), University of Dar es Salaam Business School (UDBS, 16.9\%) and College of Natural and Applied Sciences (CONAS, 12.3\%). The participant distribution largely reflected the student population at the University of Dar es Salaam, whereby CASS has the largest student population, with 4416 students (42.3\%), followed by UDBS with 1776 students (17\%), COET with 1678 students (16\%) and CONAS with 1061 students (10.2\%). All other colleges and schools have less than 10 percent of the student population at UDSM.

A majority of participants $(50.4 \%)$ were in their third year of study, followed by second year $(41.5 \%)$ and finally those in their fourth year of study $(8.1 \%)$.

The participant demographic characteristics are summarised in Table 1.

Table 1. Demographic characteristics of responding students $(\mathrm{N}=260)$

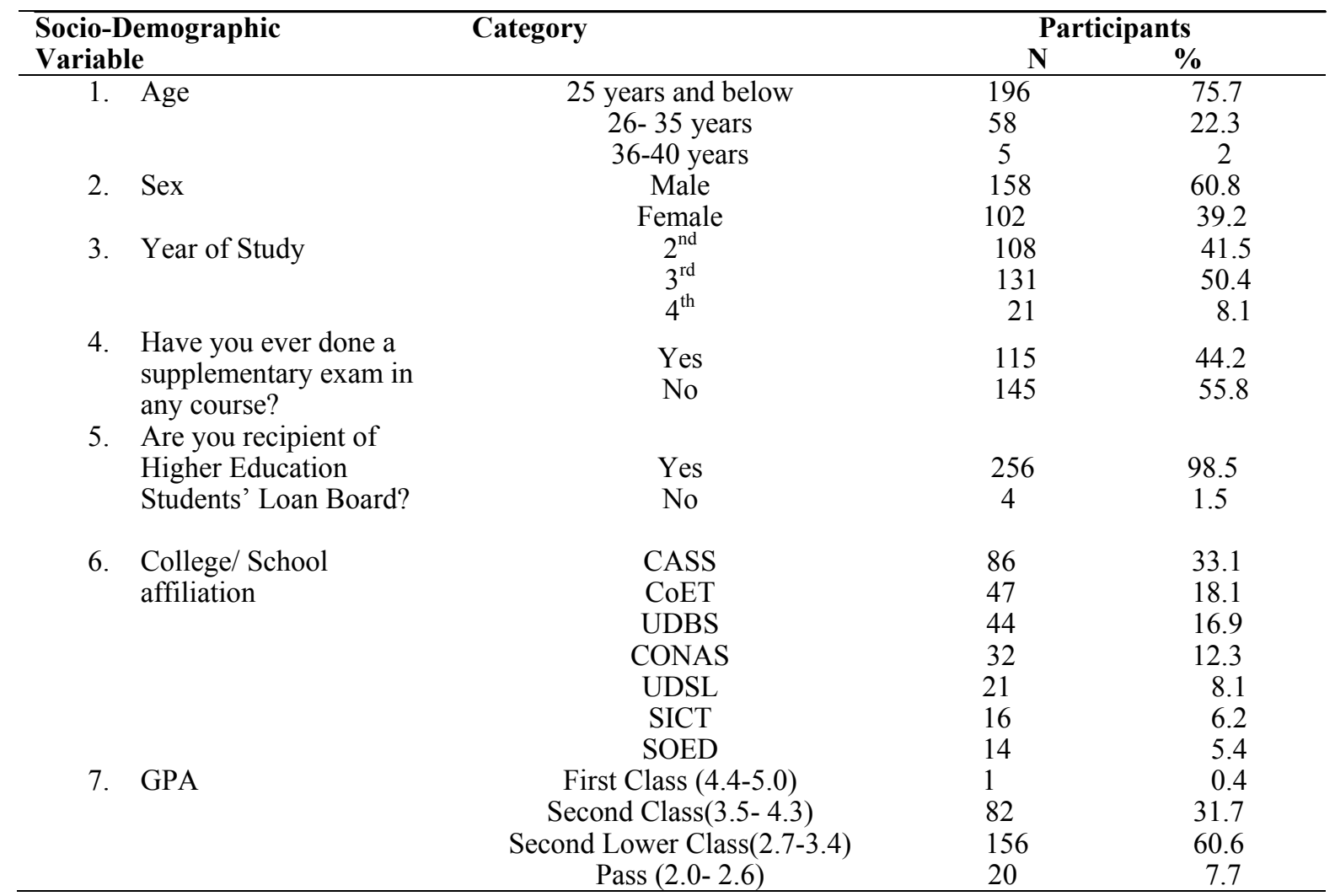




\subsection{Measures}

A questionnaire was used to collect data for this study, which consisted of three major sections. The first section consisted of items on demographic characteristics, including participant sex, age, year of study and academic performance.

Academic performance was assessed at two levels. Firstly, students were asked whether or not they had supplemented a course in the previous semester. At the University of Dar es Salaam students who do not pass a course at first sitting but obtain a certain minimum overall pass grade called Grade Points Average (GPA of 1.8 or above) are given a chance to redo another examination called supplementary examination. Of the 260 participants who completed the questionnaire, 44.2 percent indicated to have done a supplementary examination during the previous semester before completing the questionnaire. Secondly, students were requested to indicate their overall GPA during the previous semester. At the University of Dar es Salaam, GPAs are classified into four categories, namely First Class (4.4-5.0), Second Upper Class (3.5-4.3), Second Lower Class (2.7-3.4) and Pass (2.0-2.6). These were further classified into two major levels; students getting a GPA of 3.5 and above were classified as 'high performers' and those indicating to have obtained a GPA of 3.4 and below were classified as 'low performers'.

The second section consisted of ten (10) items on stability dimension, with four response options ranging from strongly agree to strongly disagree. Again, the third section of the questionnaire consisted of 10 items on controllability scale, with four response options ranging from 'Strongly Agree' to 'Strongly Disagree'. A 'strongly agree' response indicated a controllable outcome, while a 'strongly disagree' response indicated an uncontrollable outcome. The third section of the questionnaire consisted of items on locus of control. These were adopted from Rotter's (1966) scale, which measures attributions on performance on the basis of external and internal dimensions. The scale consists of 29 items, with each item consisting of two parts, 'a' and 'b'.

To test the appropriateness of the instrument to the target sample, the questionnaire was piloted to a small sample of 50 students who were eventually excluded from the study. The results of the pilot study were useful in refining and contextualising the instrument.

\section{Results}

\subsection{Students' Attribution of Their Academic Success and Failure}

Three aspects of the attribution were assessed, namely locus of control, stability and controllability. The locus of control assessed whether students attributed their academic success and failure to internal or external causes. The stability dimension looked at whether the causes that students attributed their academic success and failure were stable or unstable, that is, whether they could change in future or not. The controllability dimension assessed the aspect of whether students thought the causes for their academic performance were under their control or not. The results of each of the three dimensions are presented below.

\subsubsection{Locus of Control}

Using the Rotter's Internal-External Locus of Control Scale, students' attribution of their academic performance was assessed along internal-external dimension. The Rotter's scale has a total of 23 possible points, with a high score indicating an external locus of control and a low score indicating an internal locus of control.

The descriptive analysis revealed a score range of 5-21 $(\mathrm{M}=12.76, \mathrm{SD}=3.09)$. Of the 260 participants who completed the questionnaire, the majority of them (58.5\%) scored between $0-11$ points, implying that the majority of the students attributed their academic performance to internal causes. About 41.5 percent of the participants scored between 12 and 23 points, indicating that they attributed their academic performance to external causes.

Chi square tests were conducted to examine the variation in attribution between students who 'succeeded' in an examination and those who 'failed'. Academic success was defined as passing without supplementing a course in the previous semester, while academic failure was defined as having supplemented a course or more courses at the previous semester. The results revealed a statistically significant variation in attribution between students who supplemented an examination and those who did not: $\chi^{2}(1, \mathrm{~N}=260)=4.97, p=.03$, phi $=.13$. A higher proportion $(65 \%)$ of students who supplemented an examination attributed their academic performance to external causes than those who passed without a supplementary examination in any of the courses (see Figure 1). 


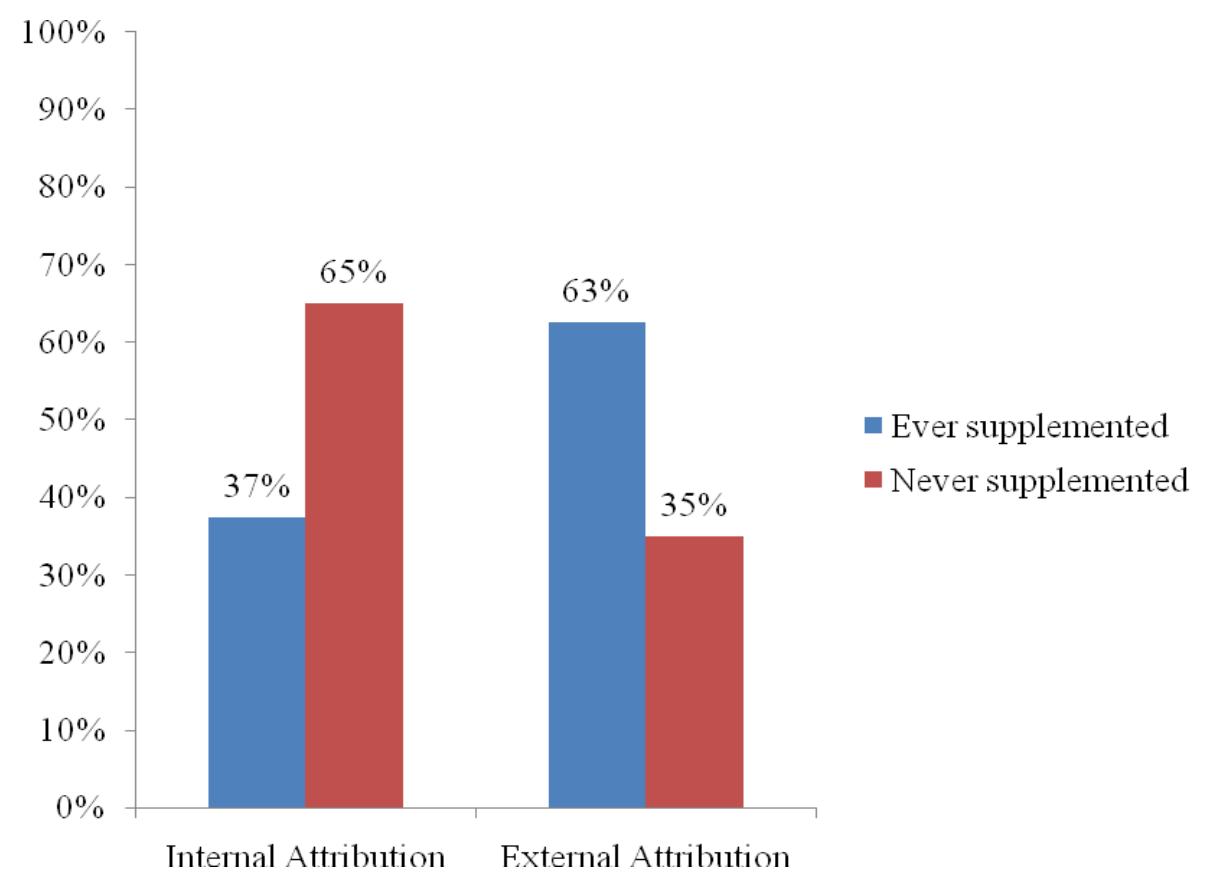

Figure 1. Variation in attribution of academic performance between students who supplemented a course and those who $\operatorname{did} \operatorname{not}(\mathrm{N}=260)$

\subsubsection{Stability Dimension}

The stability dimension was assessed using ten (10) items in which participants provided their views about their reasons for performing well or poorly in their academic tasks. These reasons were then categorised as 'stable' or 'unstable'. Stable reasons are the ones that are unlikely to change in future while unstable reasons could change in future.

The descriptive analysis revealed a score range of 15 to $28(M=20.77, S D=2.30)$. A majority of participants (63.1\%) scored below the median value, implying that the majority of them attributed their performance to unstable causes, which could change in future positively or negatively depending on their effort or other circumstances.

For example, as Table 2 shows, an overwhelming majority of the participants (95.4\%) either strongly agreed $(51.9 \%)$ or agreed $(43.5 \%)$ with the view that 'when I am successful in my examinations is due to my effort'. Furthermore, 93.4 percent of the participants either strongly agreed $(44.6 \%)$ or agreed $(48.8 \% 0$ with the view that 'the cause that made me succeed or fail is something that I can change'. Again, only 35 percent strongly agreed $(7.7 \%)$ or agreed $(27.3 \%)$ with the view that 'when I fail in my examinations it is just because of bad luck'. Chi square tests revealed no statistically significant variation in attribution along the stable dimension between low and high performing students: $\chi^{2}(3, \mathrm{~N}=260)=2.26, p=.52$, phi $=.09$.

Table 2 . Students' responses to stability dimension items

\begin{tabular}{|c|c|c|c|c|c|c|c|c|}
\hline Stability dimension item & $\begin{array}{l}\text { Strongly } \\
\text { Agree }\end{array}$ & & Agree & & Disagree & & $\begin{array}{l}\text { Strongly } \\
\text { Disagree }\end{array}$ & \\
\hline & $\mathrm{N}$ & $\%$ & $\mathrm{~N}$ & $\%$ & $\mathrm{~N}$ & $\%$ & $\mathrm{~N}$ & $\%$ \\
\hline $\begin{array}{l}\text { 1. When I am successful } \\
\text { in my examinations is } \\
\text { due to my effort }\end{array}$ & 135 & 51.9 & 113 & 43.5 & 9 & 3.5 & 6 & 1.2 \\
\hline $\begin{array}{l}\text { 2. Good mood during } \\
\text { examinations plays a } \\
\text { significant role in my } \\
\text { academic success }\end{array}$ & 171 & 65.8 & 75 & 28.8 & 9 & 3.5 & 5 & 1.9 \\
\hline $\begin{array}{l}\text { 3. I have inborn ability } \\
\text { of analysing what has }\end{array}$ & 58 & 22.3 & 120 & 46.2 & 40 & 15.4 & 42 & 16.2 \\
\hline
\end{tabular}




\begin{tabular}{|c|c|c|c|c|c|c|c|c|}
\hline Stability dimension item & \multirow{2}{*}{$\begin{array}{c}\begin{array}{c}\text { Strongly } \\
\text { Agree }\end{array} \\
\mathrm{N}\end{array}$} & \multicolumn{3}{|c|}{ Agree } & \multirow{2}{*}{$\begin{array}{c}\text { Disagree } \\
\mathrm{N}\end{array}$} & \multicolumn{3}{|c|}{$\begin{array}{l}\text { Strongly } \\
\text { Disagree }\end{array}$} \\
\hline & & $\%$ & $\mathrm{~N}$ & $\%$ & & $\%$ & $\mathrm{~N}$ & $\%$ \\
\hline be taught in class & & & & & & & & \\
\hline $\begin{array}{l}\text { 4. When I fail in my } \\
\text { examinations it is just } \\
\text { because of bad luck }\end{array}$ & 20 & 7.7 & 71 & 27.3 & 90 & 34.6 & 79 & 30 \\
\hline $\begin{array}{l}\text { 5. I have good memory } \\
\text { to remember the } \\
\text { course content well }\end{array}$ & 52 & 20 & 162 & 62.3 & 36 & 13.8 & 10 & 3.8 \\
\hline $\begin{array}{l}\text { 6. I was not as careful as } \\
\text { usual }\end{array}$ & 25 & 9.6 & 76 & 26.2 & 101 & 38.8 & 58 & 22.3 \\
\hline $\begin{array}{l}\text { 7. I feel more proud } \\
\text { when a teacher gives } \\
\text { me an 'A' than when a } \\
\text { teacher gives me a ' } \mathrm{C} \text { ' }\end{array}$ & 157 & 60.4 & 67 & 25.8 & 28 & 10.8 & 8 & 3.1 \\
\hline $\begin{array}{l}\text { 8. I am always calm for } \\
\text { whatever grade I get } \\
\text { because I deserve it }\end{array}$ & 27 & 10.4 & 65 & 25 & 89 & 34.2 & 79 & 30.4 \\
\hline $\begin{array}{l}\text { 9. The cause that made } \\
\text { me succeed or fail is } \\
\text { something that can } \\
\text { change }\end{array}$ & 116 & 44.6 & 127 & 48.8 & 13 & 5 & 4 & 1.5 \\
\hline $\begin{array}{l}\text { 10. I think I can do well in } \\
\text { the next coming } \\
\text { examinations }\end{array}$ & 161 & 61.9 & 91 & 35 & 4 & 1.5 & 4 & 1.5 \\
\hline
\end{tabular}

\subsubsection{Controllability Dimension}

The controllability dimension was assessed on a ten scale with four response options ranging from 'strongly agree' to 'strongly disagree'. A majority of participants scored beyond the average median value (25), with the implication that the majority of them attributed their academic performance to controllable factors.

Table 3 summarises the responses on the ten items. Generally, a majority of participants attributed their performance to controllable factors. For example, 60.4 percent of participants strongly agreed (20\%) and agreed (40.4\%) that 'intelligence has nothing to do with my performance but rather my own effort'. Similarly, 92.3 percent of participants strongly agreed (58.1\%) and agreed (34.2\%) with the view that 'no matter how difficult examinations can be proper preparation matters'.

Nevertheless, a substantial proportion of participants attributed their performance to factors that are clearly uncontrollable. For example, a substantial proportion of participants attributed their performance to 'biased teachers', with 57.7 percent of participants strongly agreeing $(26.2 \%)$ and agreeing $(31.5 \%)$ that 'no matter how hard I try still I could not compete with biased teachers'. Additionally, a significant proportion of participants attributed their performance to 'luck', with 68.5 percent of them strongly agreeing (10.8\%) and agreeing (57.7\%) with the statement that 'I am so luck that in most of my courses my performance is good'. Again, success or failure was associated with 'easy or difficult' exams, in which 71.9 percent of participants strongly agreed $(28.8 \%)$ and agreed (43.1\%) with the view that 'success or failure depends on how easy or difficulty the exams could be'.

Chi square tests were conducted to assess the variation in attribution with respect to controllability between high performing and low performing students. The results revealed a statistically significantly higher proportion of lowly performing students attributing their performance to uncontrollable factors than highly performing students: $\chi^{2}(3, \mathrm{~N}=260)=2.26, p=.02, \mathrm{phi}=.19$. 
Table 3. Students' responses to controllability dimension items

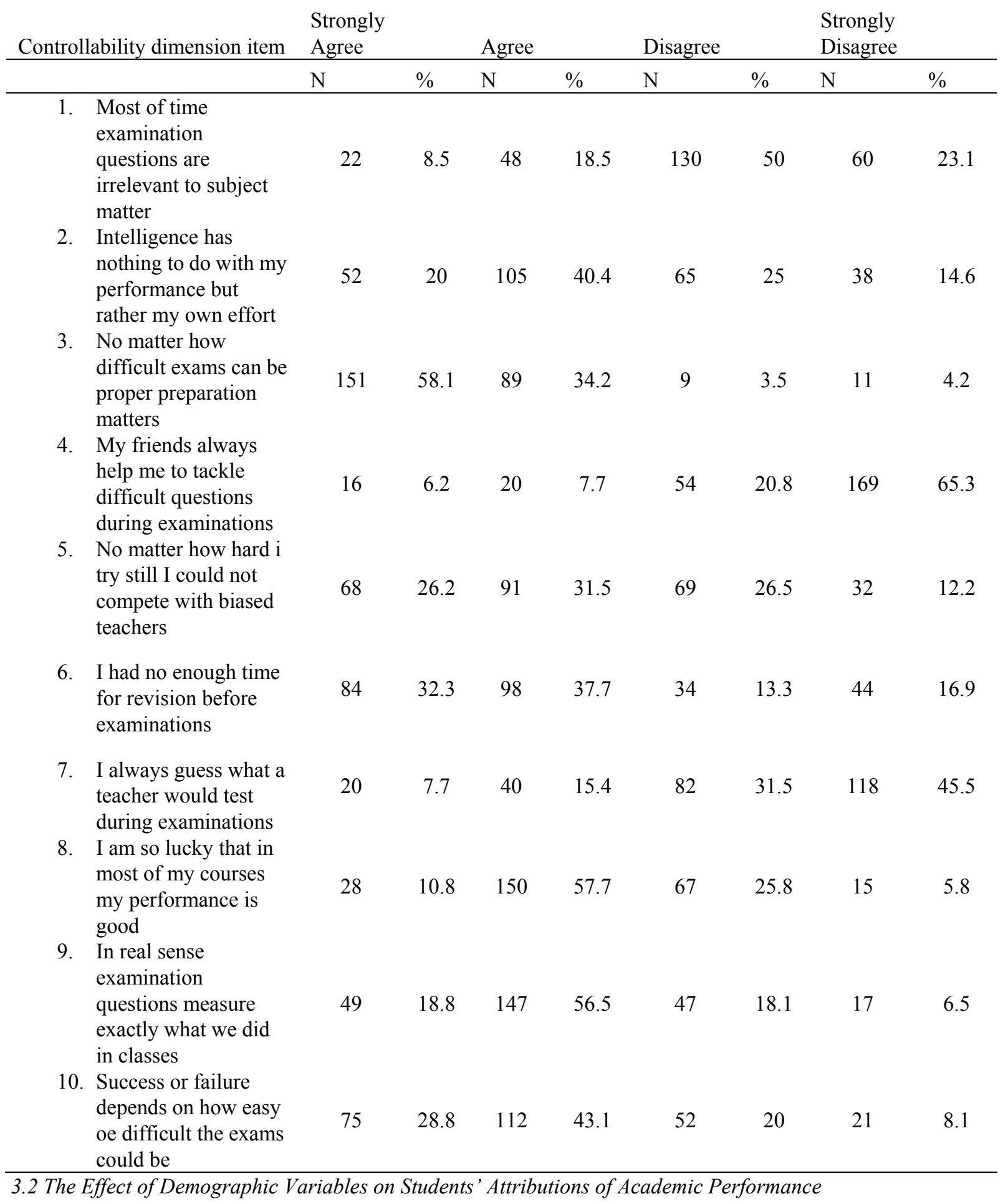

Chi-square tests were conducted to examine the variation in students' attributions of their academic performance with respect to sex, age, year of study and college/school affiliation. The results showed that only sex showed a statistically significant variation, with a higher proportion $(80.3 \%)$ of female respondents attributing their performance to internal factors than male respondents (68.7\%). The results of Chi-square tests are summarised in Table 4. 
Table 4. Variation in students' attributions by demographic characteristics

\begin{tabular}{ccccc}
\hline Variable & $\boldsymbol{X} \mathbf{2}$ & $\boldsymbol{d} \boldsymbol{f}$ & $\boldsymbol{N}$ & $\boldsymbol{p}$ \\
\hline Sex & 4.43 & 1 & 260 & .04 \\
Age & 17.73 & 17 & 260 & .41 \\
College/school & 8.07 & 6 & 260 & .23 \\
affiliation & 1.66 & 2 & 260 & .44 \\
Year of Study & & & & \\
\hline
\end{tabular}

\section{Discussion}

This study has assessed the relevance and applicability of the attribution theory in understanding how students in higher education attribute their academic success and failure. The study specifically assessed the variation in attribution of academic performance between high performing and low performing students.

The results show that, generally, the majority of students tend to attribute their academic performance to internal, unstable and controllable factors. High performing students are more likely to attribute their academic performance to internal causes than low performing students. In this case, there was a statistically significant variation in attribution with respect to locus of control between high performing and low performing students. Furthermore, the results show that high performing students are more likely to attribute their academic performance to controllable factors than low performing students. With the exception of sex, the students' attribution pattern was no associated with any of the demographic variables studied. There was a statistically significant variation in attribution between female and male students, with a higher proportion of female students attributing their academic performance to internal causes than their male counterparts.

The results of this study largely confirm the basis of the attribution theory, as well as findings of previous similar studies in demonstrating that, generally, people tend to attribute success to internal and controllable factors, while attributing failure to some external and uncontrollable factors. In this case, successful and high performing students attributed their academic success to internal and controllable factors, while failing and low performing students attributed their academic failure to external and uncontrollable factors. This pattern of attribution was also established in previous studies such as Linder \& Janus (1977), Augoustinos (2005), Boruchovitch (2004) and Brown, Gray \& Ferrara (2005).

The fact that, with the exception of sex, there was no statistically significant association between students' demographic variables and their attribution pattern is a further confirmation that effort may be a more important determinant of academic performance than personality traits. Though there was a statistically significant variation in attribution to academic performance between male and female participants, this variation did not correspond with variation in actual performance. That is, there was no statistically significant variation in academic performance between male and female students. This particular finding contradicts the previous findings by Batool, Arif and Ud Din (2009) who established that female students tended to attributed internally while male students attributed externally, and impliedly this made female students perform better than male students. However, further studies are needed to explain the variation in attribution between male and female students.

\section{Conclusions and Recommendations}

The results of this study confirm the predictions of the attribution theory and are in line with the findings of many other previous similar studies conducted elsewhere with different populations. The results generally support the basis of the attribution theory that success is always attributable to internal factors, while failure is attributed to external factors.

The results of the present study should be interpreted with one caveat. The participants for the study were recruited conveniently rather than randomly. As such, generalisation of the findings should be done with great care as the sample was not wholly representative. Nevertheless, given the homogeneity of the population from which the sample was drawn, the results should be largely relevant and applicable to other similar settings.

These results point out some important implications for students, teachers and university authorities. As stated by Hunter and Barker (1987), 'students should accept the fact that much of what happens to them is a result of what they do'. As such they should focus on effort as the main driver of success in their academic endeavours rather than luck or ability. Teachers, on the other hand, should adjust the way they interact with and respond to students' performance by appreciating the fact that every student can learn to learn and therefore every student can be successful. These results therefore have implications in demystifying the self-fulfilling prophecy, which can be detrimental in teachers' handling of their students learning endeavours. 
It is also recommended that university authorities should always emphasise effort as the basis of students' success in their academic activities, while improving the learning environment so as to minimise environmental constraints. Future studies should attempt to examine the sex variation in attribution, and particularly the reasons as to why female students attribute internally and why male students tend to attribute externally.

\section{References}

Augoustinos, M. (2005). Social Cognition : An Integrated Introduction. New Delhi: Sage Publication.

Banks, M., \& Woolfson, L. (2008). Why do students think they fail? The relationship between attributions and academic self-perceptions. British Journal of Special Education, 35(1), 49-56. http://dx.doi.org/10.1111/j.1467-8578.2008.00369.x

Batool, S., Arif., M.H., \& Ud Din, M.N. (2010). Gender differences in performance attributions of mainstream and religious school students. International Journal of Academic Research, 2(6), 454-458. Retrieved from www.ijar.lit.az/pdf/8/2010(6-70).pdf

Boruchovitch, E. (2004). A study of causal attributions for success and failure in mathematics among Brazilian students. Interamerican Journal of Psychology, 38(1), 53-60. Retrieved from www.psicorip.org/Resumos/PerP/RIP/RIP036a0/RIP03807.pdf

Brown, R. A., Gray, R. R., \& Ferrara, M. S. (2005). Attributions for personal achievement outcomes among Japanese, Chinese, and Turkish university students. Information and Communication Studies, 33(1), 1-14.

Heider, F. (1958). Psychology of Interpersonal Relations. New York: Wiley. http://dx.doi.org/10.1037/10628-000

Hunter, M., \& Barker, G. (1987). "If at first...”:Attribution theory in the classroom. Educational Leadership, 45(2), 50-53. Retrieved from www.ascd.org/ASCD/pdf/journals/ed_lead/el_198710_hunter.pdf

Keith, T. Z., Pottebaun, S. M., Sheila, M., \& Eberhat, S. (1986). Effects of self-concept and locus of control on academic achievement: a large-sample path analysis. Journal of Psychoeducational Assessment, 14(1), 6172. http://dx.doi.org/10.1177/073428298600400107

Laherand, M.L., \& Putnina, M. (2007). Students' causal attributions for their academic success and failure-similar or different in neighbour countries? Paper Presented at $5^{\text {th }}$ International JTET Conference on Theories and Practices for Education of Sustainable Development: Debrecen: University of Debrecen 23-24 November. Retrieved from www.ut.ee/orb.aw/class=file/action.../Laherand,+Putina+28.10.pdf

Lei. C. (2009). On causal attribution of academic achievement in college students. Asian Social Science, 5(8), 87-96. Retrieved from http://www.ccsenet.org/journal/index.php/ass/article/download/3444/3118

Linder. F., \& Janus. C. E. (1997). The relationship of locus of control to academic performance among dental students. Paper Presented at the Annual Meeting of Eastern Educational Research Association, Hitton Head, Sc.

Murray, J., \& Thomson, M.E. (2009). An application of attribution to clinical judgement. Europe's Journal of Psychology, 3, 96-104.

Weiner, B. (1985). An attributional theory of achievement motivation and emotion. Psychological Review, 92(4), 548-573. http://dx.doi.org/10.1037/0033-295X.92.4.548 